\title{
EBN Opinion
}

Dr David Barrett, Director of Pre-Registration Nurse Education, University of Hull

\section{Fields of nursing: do we need them, what should they be and when should nurses choose theirs?}

This month's opinion relates to an EBN twitter chat that explored the value of fields of nursing and their future within the United Kingdom ( http://blogs.bmj.com/ebn/2016/11/10/fields-of-nursing-do-we-needthem-what-should-they-be-and-when-should-nurses-choose-theirs/ ).

\section{Background}

In the United Kingdom (UK), pre-registration nurse education provides a route into one of four 'nursing fields' - Adult, Child, Learning Disabilities and Mental Health. Student nurses select their chosen field at the time of application to University, and then complete a degree (or higher) level programme of study focused on that field (albeit with some shared elements across fields). This early choice of field therefore shapes a nurse's practice focus for their subsequent career.

The rationale for this field-based structure to the registered nurse workforce is a simple one - by providing entrants to the nursing profession with a skill set focused on a particular client group, they will be better able to provide specialist, evidence-based care. However, the current model is not without its critics. Most notably, the latest review of nurse education in the UK (entitled Shape of Caring) has suggested that the current system does not produce flexible practitioners with the transferable skills necessary to work with patients and clients in a range of settings (Willis, 2015). The review proposes a more generic model, specifically suggesting that students complete two-year 'whole-person' education, before specialising in the final year of their programme and first year post-registration (the so-called $2+1+1$ model).

Since the publication of Shape of Caring, concerns have been raised about this proposed, more generic model. The potential implications of a more generic approach to the nursing workforce have been outlined in particular relation to Mental Health (McKeown \& White, 2015), Learning Disabilities (McClimens \& Burns, 2016) and Child (Twycross \& Smith, 2016) fields. These discussions highlight the need to endow student nurses with the specialist skills and knowledge required to care for their client groups, and argue that a more generic educational approach may lead to dilution of those skills.

There is, of course, no question that nurses caring for specific client groups need to develop a specific set of knowledge and skills to supplement their core nursing competences. This is applicable not just to those areas of care with existing fields, but also sub-specialities such as palliative care or primary care nursing. The issue then is not whether nurses need to specialise, but at what stage? Should student nurses make a choice of specialism - a decision that will dictate the course of their entire career - when they enter University, or would this decision be better informed if made further into a programme of study? Is the ideal model one of a generic nurse workforce that specialises only when working in a particular area following registration? With complex issues such as this, it is often useful to be guided by practice globally. Unfortunately, it is difficult to learn much about specialisation from nursing at an international level, because practice is so disparate. Though there are some countries that operate a system of entry-level specialism similar to the UK, others adopt a completely generic model within pre-registration education (including generic pre-registration preparation of nurses and midwives) (Nichols et al, 2011)

In parallel with discussion of when specialisation takes place, there is also debate on how many fields of nursing there needs to be. Shape of Caring advocates the development of an additional field in community care, but there is also support within the profession for a pre-registration specialism in care of older people. The number and foci of specialist fields will always be a matter of debate and will often change according the needs of the population (for example, there was still a specific place on the UK nursing register for Fever Nurses until the mid-1960s). However, whilst the idea of new fields may be superficially attractive for those working in those areas, care must be taken not to try to fragment the nursing community to an extent where there is a danger of 'silo' working and a loss of core identity. 


\section{Key messages from the Twitter Chat (\#ebnjc)}

There was recognition amongst participants of the potential strengths and weaknesses associated with a field-based model of nursing. In particular, there were concerns that fields encouraged 'silo' care that reduced the ability of nurses to care for a wide range of patient groups. For example, there was a perception that adult field nurses may not feel capable of meeting the mental health needs of their patients (and, conversely, that mental health nurses may not adequately understand physical health needs). As a result, there was some support for the more generic model of education advocated by the Shape of Caring.

One particularly interesting area of discussion was when nurses should seek to specialise in a particular field or area of care. Though some participants argued that making a decision at point of entry to education was appropriate, others supported more generic pre-registration education, supplemented with a wider portfolio of post-registration education.

\section{Where next?}

The extent to which the recommendations of the Shape of Caring are implemented will become apparent over the coming months and years. It is possible that we may see adoption of a ' $2+1+1$ ' model of nurse preparation, with or without alterations in the number and focus of nursing fields.

Whatever the future, the profession must ensure that a balance is struck that provides nurses with specialist skill sets, but does not reduce their ability to provide fundamental care to people with a broad range of needs.
Example Tweets from EBN Twitter chat exploring fields of nursing

A broader range of Tweets can be found at: https://storify.com/barrett1972/ebn-twitter-chat-fields-of-nursing

What are the main strengths and weaknesses of a field-based nursing structure?

Prof Alison Twycross

@alitwy

Follow

Think the four fields encourage silo care and mean nurses can't always care for all patient needs \#ebnjc

8:08 PM - 16 Nov 2016

\& 2701

Prof Alison Twycross

@alitwy

Follow

Adult nurses don't feel capable of caring for people with mental health problems. MH nurses not able to care for physical needs \#ebnjc twitter.com/barrett1972/st...

8:06 PM - 16 Nov 2016

4 2 ᄂ?

Do we need more fields, less fields, or no fields?

Amanda Bowman

@amanda6679

Follow

@barrett1972 @Stephen8McK two fields; adult and child with LD/MH integrated throughout. 4 years, more practice experience \#ebnjc

8:59 PM - 16 Nov 2016

4 2 เา 1

\section{$\because \because$ Meriel Chudleigh}

@MerielChudleigh

Follow

\#ebnjc 'Adult' nurse here: I am keen for $\mathrm{MH} /$ child in all nurse education.Community field not needed: part of all (Com nurse since1997) twitter.com/EBNursingBMJ/s...

8:41 PM - 16 Nov 2016

\& 4701

When should nurses choose their field/specialism?

\section{Stephen McKeever}

@Stephen8McK

@barrett1972 \#ebnjc from a paed perspective 'on entry' with a retrain option for those who want to join later

8:33 PM - 16 Nov 2016

\& 27

\section{Brian McGowan}

@BriMcgowan

Follow

@barrett1972 @Stephen8McK \#ebnjc Theres also the single registration with postgrad college model to consider?

8:41 PM - 16 Nov 2016 


\section{References}

McClimens A, Burns S (2016) Looking after people with learning disabilities part three: who will care? Learning Disability Practice 19(3): 28-32

McKeown M, White J The future of mental health nursing: are we barking up the wrong tree? Journal of Psychiatric and Mental Health Nursing, 22: 724-730

Nichols BL, Davis CR, Richardson DR (2011) International models of nursing. In: Committee on the Robert Wood Johnson Foundation Initiative on the Future of Nursing, at the Institute of Medicine. The future of nursing: Leading change, advancing health. Washington D.C, National Academies Press. 565-639. Available at: https://www.ncbi.nlm.nih.gov/books/NBK209879/\#top [4 ${ }^{\text {th }}$ November 2016]

Twycross A, Smith J (2016) Shape of caring review: impact for children's nursing education. Evidence-Based Nursing. 18:105-106.

Willis T (2015) Raising the Bar. Shape of Caring: A Review of the Future Education and Training of Registered Nurses and Care Assistants Available at https://www.hee.nhs.uk/sites/default/files/documents/2348-Shapeof-caring-review-FINAL.pdf $\left[6^{\text {th }}\right.$ November 2016] 